\title{
Worry, Severity, Controllability, and Preventive Behaviours of COVID-19 and Their Associations with Mental Health of Turkish Healthcare Workers Working at a Pandemic Hospital
}

\author{
Murat Yıldırım $^{1,2}$ (D) Ahmet Özaslan ${ }^{3}$ \\ Accepted: 24 February 2021/Published online: 3 March 2021 \\ (C) Springer Science+Business Media, LLC, part of Springer Nature 2021
}

\begin{abstract}
Previous research suggests that psychological and behavioural factors such as worry, severity, controllability, and preventive behaviours are associated with mental health and well-being. Less is known about simultaneous effects of those factors in predicting mental health and well-being. This study aimed to present the prevalence of mental health problems and identify the predictors of mental health and subjective well-being of healthcare workers during the COVID-19 pandemic. Participants included 245 healthcare workers $\left(M_{\text {age }}=33.16 \pm 7.33 ; 50.61 \%\right.$ females $)$ from a pandemic hospital in Turkey. Healthcare workers reported mild/severe depression, anxiety, and stress. Females tended to be more vulnerable to developing psychiatric symptoms. Worry, severity, and controllability significantly predicted depression, anxiety, stress, and subjective well-being while preventive behaviours only predicted subjective well-being. These findings suggest the importance of assessing healthcare workers' experiences of mental health and subjective well-being and their associated factors to assist mental health providers tailor assessments and treatment during a pandemic.
\end{abstract}

Keywords Worry $\cdot$ Severity $\cdot$ Controllability $\cdot$ Preventive behaviours $\cdot$ Mental health problems · Subjective well-being

\section{Murat Yildırım}

muratyildirimphd@gmail.com; muratyildirim@agri.edu.tr

1 Department of Psychology, Faculty of Science and Letters, Ağr1 İbrahim Çeçen University, Erzurum Yolu 4 Km 04100, Merkez, Ağrı, Turkey

2 Department of Neuroscience, Psychology and Behaviour, University of Leicester, Leicester, UK

3 Department of Child and Adolescent Psychiatry, Gazi University, Ankara, Turkey 
Severe acute respiratory syndrome caused by a novel coronavirus (COVID-19) is an extremely contagious, serious, and potentially life-threatening form of pneumonia. The first confirmed case of COVID-19 was reported in Wuhan, China, in late December 2019. As of February 2, 2021, more than 105,774,900 cases had been reported in at least 192 countries, including the first confirmed case of COVID-19 with a total of 2,524,786 cases in Turkey, reported on March 11, 2020 (Center for Systems Science and Engineering 2021). Investigations are under way around the world, not only to understand transmission dynamics and the spectrum of clinical disease but also determine psychological and behaviours factors associated with mental health of people.

The virus manifested its impact in many areas including healthcare settings. Healthcare workers (HCWs) are at high risk of infection, and their mental health have been severely affected during the pandemic (Yildirım et al. 2020b, b). The World Health Organization (WHO 2020) highlighted the excessive burden of COVID-19 on HCWs and called for urgent action to address the basic needs and measures necessary to save lives and prevent serious impact of pandemic on HCWs' physical and mental health. HCWs are under pressure due to overwork, lack of supplies, and more exposure to negative emotions from the patients. The challenges faced by HCWs include not only being overwhelmed by increased work overload but also the continuous fear, worry, and anxiety for themselves and their families (Yildirım et al. 2021a, b), working with new and frequently changing protocols and personal protective equipment. These factors can trigger both the emergence of new mental health problems and the exacerbation of pre-existing problem (Hao et al. 2020; Kang et al. 2020; Xiang et al. 2020; Yıldırım and Güler 2020).

HCWs directly involved in the care of patients with COVID-19 are at high risk of developing psychological distress and other mental health symptoms such as posttraumatic stress symptoms (Carmassi et al. 2020). Empirical evidence in the context of COVID-19 pandemic showed that HCWs experience severe symptoms of anxiety, depression, and stress (Lai et al. 2020). For example, in a systematic review and meta-analysis of 13 studies, Pappa et al. (2020) documented high rates of anxiety $(23.2 \%$,), depression $(22.8 \%)$, and insomnia $(38.9 \%)$ in HCWs, with female HCWs exhibiting higher rates of affective symptoms. Studies on previous outbreaks such as severe acute respiratory syndrome (SARS) in 2003 Middle East respiratory syndrome (MERS) in 2015 also reported high levels of mental health problems including anxiety, depression, and sleep disorders among HCWs in many countries (Bai et al. 2004; Lee et al. 2018; Maunder et al. 2004).

\section{Psychological and Behavioural Factors Affecting Mental Health of HCWs}

There are various psychological and behavioural factors affecting mental health of HCWs in the context of pandemic. Worry appears to be an important risk factor for mental health during global health crisis. The rates of worry are high among HCWs during the pandemic. Puci et al. (2020) identified the levels of worries among Italian HCWs and found that HCWs were worried about the COVID-19 infection with a median score of 3 , measured on a score ranging between 0 (not worried) and 4 (very worried). Higher levels of COVID-19 related worry were also found to be associated with greater mental health disorders and resilience and meaning in life mediated the impact of COVID-19 related worry on mental health disorders (Yıldırım et al. 2020a). 
Severity of a disease also has a tremendous impact on general health and well-being across (Vilhena et al. 2014). According to the protection motivation theory, public perception about severity of disease is affected by its possible physical damage to health (Rogers 1975). Evidence from previous outbreaks like SARS indicated that greater level of severity is related with lack of knowledge about diseases leading to diminished mental health (de Zwart et al. 2009). Although limited, studies conducted during current pandemic showed that COVID-19 severity is significantly and negatively related to general mental health, self-efficacy, and knowledge about the disease, while it was significantly positively related to preventive behaviours against the virus (Yıldırım and Güler 2020).

Although controllability of a disease does not appear to have been studied in the context of pandemics, it is possible that people with high levels of controllability of a disease have better mental health and well-being during the COVID-19 crisis. Studies demonstrated that beliefs about the controllability of a disease is associated with better functioning and mental health such low depression (Boonen 2010). Therefore, it can be assumed that controllability is a critical determinant of mental health outcomes.

In addition to psychological factors, the ways individuals cope with stressful events have also been indicated to be a significant factor in preventing adverse effects of the pandemic. People tend to engage in preventive behaviours as a way to mitigate the risk of infection (Yıldırım et al. 2021a). Evidence suggests that people who engaged in protective behaviours report better general health in the context of pandemic (Yıldırım and Güler 2020). For example, in a study conducted by Yıldırım and Arslan (2020), preventive behaviours against COVID-19 were associated with high resilience which in turn promote psychological health. The lack of practice on the preventive behaviours against COVID-19 may also lead to the increase in COVID-19 cases among HCWs (Bashirian et al. 2020; Chou et al. 2020).

\section{Present Study}

Thus far, all the aforementioned factors influence mental health and well-being, but little is known about how they predict mental health and well-being of HCWs during the COVID-19 pandemic. Earlier studies investigated single risk factor or a small set of risk factors in relation to mental health. Examining each factor as an independent hypothesis, as done in previous studies, can result in incorrect conclusions due to several comparison, multicollinearity, and model misspecification. Therefore, the aims of the present study were threefold: (i) to describe the prevalence of anxiety, depression, and stress among HCWs during COVID-19; (ii) to compare male and female HCWs in terms of worry, control, severity, preventive behaviours, depression, anxiety, stress, and subjective well-being; and (iii) to examine how worry, control, severity, and preventive behaviours would predict mental health and subjective well-being.

\section{Method}

\section{Participants}

The sample comprised of 245 healthcare workers from a pandemic hospital in Turkey. The sampling approach was convenience due to the accessibility. No exclusion criterion was employed for the hospital. The hospitals which accepted to participate were included. 
Participants ranged in age between 22 and 58 years $\left(M_{\text {age }}=33.16 \pm 7.33\right)$. There was almost equal number of males (49.39) and females (50.61\%). Most participants were married (64.10\%), had a high level of educational attainment (53.06\% at least a bachelor's degree), and had no chronic medical conditions such as diabetes and cancer (73.47\%). The majority of participants were doctors $(42.04 \%)$ and nurses $(24.90 \%)$. The results are presented in Table 1.

\section{Measures}

Worry By specifying the COVID-19 pandemic, a single item (Andersen et al. 2003) was used to assess worry related to COVID-19: "During the past 4 weeks, how often have you thought about your chances of getting coronavirus?". The item is rated on a 5-point Likert-type scale ranging from $1=$ not at all to $5=$ most all the time, with higher scores referring to a higher level of worry pertaining to COVID-19.

Severity To assess the level of severity related to COVID-19, a single item was utilized: "How serious would it be for you if you contract COVID-19 in the next year?" (de Zwart et al. 2009; Yıldırım and Güler 2020). The item is answered on a 5-point Likert-type scale ranging from $1=$ not at all to $5=$ very serious, with higher scores indicating greater severity related to COVID-19.

Controllability By specifying the COVID-19 pandemic, a single item (Witte 1996) was used to measure controllability corresponding to COVID-19: "There's a lot I can do to prevent coronavirus". The item is rated on a 5-point Likert-type scale ranging from $1=$ strongly disagree to $5=$ strongly agree, with higher scores indicating greater level of controllability of COVID-19.

Preventive Behaviours The measure for the preventive behaviours of COVID-19, assessed on nine items with 5-point scales ranging from $1=$ never to $5=$ always, was adapted from preventive behaviours scale (Yıldırım and Güler 2020). A higher score indicates higher engagement in preventive behaviours against COVID-19.

Table 1 Characteristics of the sample $(n=245)$

\begin{tabular}{|c|c|c|c|}
\hline Variable & Level & Frequency & Percent \\
\hline \multirow[t]{2}{*}{ Gender } & Males & 121 & 49.39 \\
\hline & Females & 124 & 50.61 \\
\hline \multirow[t]{3}{*}{ Marital status } & Married & 157 & 64.10 \\
\hline & Single & 76 & 31.00 \\
\hline & Divorced/widowed & 12 & 4.90 \\
\hline \multirow[t]{3}{*}{ Educational attainment } & High school or lower & 40 & 16.33 \\
\hline & Bachelor's degree & 130 & 53.06 \\
\hline & Master's degree/PhD & 75 & 30.61 \\
\hline \multirow[t]{3}{*}{ Having chronic diseases } & Yes & 49 & 20.00 \\
\hline & No & 180 & 73.47 \\
\hline & Do not know & 16 & 6.53 \\
\hline \multirow[t]{4}{*}{ Professions } & Doctor & 103 & 42.04 \\
\hline & Nurse & 61 & 24.90 \\
\hline & Allied health workers & 18 & 7.35 \\
\hline & Other & 63 & 25.71 \\
\hline
\end{tabular}


Mental Health To assess mental health problems, the depression anxiety stress scales-21 (DASS-21) was used (Lovibond and Lovibond 1995). The DASS-21 contains 21 items clustered into three subscales ( 7 items per subscale): depression, anxiety, and stress. The scale uses a 4-point Likert-type, where 0 refers to "did not apply to me at all" to 3 presents "applied to me very much or most of the time". Higher scores refer to high depression, anxiety, and stress. The scale had good evidence of reliability and validity in Turkish (Sarıçam 2018).

Subjective Well-Being To assess the HCWs' subjective well-being, we used the World Health Organization-5 well-being index (WHO-5; Staehr 1998). The WHO-5 includes five items rated on a 6-point Likert scale response format that ranges from $0=$ not present to $5=$ constantly present. The scale was translated into Turkish Eser et al. (2019).

\section{Design}

Participants were invited and filled out an online survey prepared on Google Forms and distributed through social networking sites (e.g. WhatApp). The research used an online snowball technique to recruit participants. All participants provided their informed consent (online) to take part in this study after being fully informed about the purpose and procedures of the current study. The study protocol was carried out in line with the ethical principles established in the Declaration of Helsinki. The procedure was approved by the ethical committee of a state university (anonymised) and Republic of Turkey Ministry of Health.

\section{Data Analysis}

This study employed descriptive statistics and regression analysis. Skewness and kurtosis values fell within an acceptable level of normal distribution (skewness = -0.02 and 1.29; kurtosis $=-0.01$ and -2.02 ). There was no missing data. Internal consistency reliability ranged between acceptable to excellent. An independent sample $t$ test was run to compare male and female groups on the study variables. Pearson product-moment correlation was calculated to explore the bivariate correlations between the analysed variables of this study. Hierarchical multiple regression analysis was conducted to examine the roles of demographic, psychological, and behavioural factors in predicting mental health and subjective well-being. A probability $p$ value of less than 0.05 was considered statistically significant. The statistical analyses were conducted with SPSS 25 for Windows.

\section{Results}

\section{Rates of Healthcare Workers' Mental Health Problems}

Table 2 presents the rates of mental health problems reported by healthcare workers. Rates for likely common mental health problems were lower but still high, with $2.45-12.65 \%$ (depression), 2.40-9.40\% (anxiety), and 3.70-6.10\% (stress) scoring falling within the mild/severe score range. 
Table 2 Rates of depression, anxiety, and stress

\begin{tabular}{|c|c|c|c|c|c|c|c|c|c|}
\hline \multirow[b]{2}{*}{ Severity level } & \multirow[b]{2}{*}{ Cut-off score } & \multicolumn{2}{|c|}{ Overall } & & \multicolumn{2}{|c|}{ Males } & & \multicolumn{2}{|c|}{ Females } \\
\hline & & $\mathrm{n}$ & $\%$ & & $\mathrm{n}$ & $\%$ & & $\mathrm{n}$ & $\%$ \\
\hline Normal & Depression $\leq 9$ & 195 & 79.59 & & 105 & 86.78 & & 90 & 72.58 \\
\hline Mild & $10 \leq$ Depression $\leq 13$ & 31 & 12.65 & & 10 & 8.26 & & 21 & 16.94 \\
\hline Moderate & $14 \leq$ Depression $\leq 20$ & 13 & 5.31 & & 4 & 3.31 & & 9 & 7.26 \\
\hline Severe & $21 \leq$ Depression $\leq 27$ & 6 & 2.45 & & 2 & 1.65 & & 4 & 3.23 \\
\hline Extremely severe & Depression $\geq 28$ & - & - & - & - & - & - & - & - \\
\hline Normal & Anxiety $\leq 7$ & 201 & 82.00 & & 109 & 90.08 & & 92 & 74.19 \\
\hline Mild & $8 \leq$ Anxiety $\leq 9$ & 15 & 6.10 & & 8 & 6.61 & & 7 & 5.65 \\
\hline Moderate & $10 \leq$ Anxiety $\leq 14$ & 23 & 9.40 & & 2 & 1.65 & & 21 & 16.94 \\
\hline Severe & $15 \leq$ Anxiety $\leq 19$ & 6 & 2.40 & & 2 & 1.65 & & 4 & 3.23 \\
\hline Extremely severe & Anxiety $\geq 20$ & - & - & - & - & - & - & - & - \\
\hline Normal & Stress $\leq 14$ & 221 & 90.20 & & 113 & 93.39 & & 108 & 87.10 \\
\hline Mild & $15 \leq$ Stress $\leq 18$ & 15 & 6.10 & & 5 & 4.13 & & 10 & 8.06 \\
\hline Moderate & $19 \leq$ Stress $\leq 25$ & 9 & 3.70 & & 3 & 2.48 & & 6 & 4.84 \\
\hline Severe & $26 \leq$ Stress $\leq 33$ & - & - & - & - & - & - & - & - \\
\hline Extremely severe & Stress $\geq 34$ & - & - & - & - & - & - & - & - \\
\hline
\end{tabular}

\section{Gender Differences on Healthcare Workers' Mental Health Problems and COVID-19-Related Factors}

As presented in Table 3, the means of worry (3.60 vs. 3.83; $p<0.05$ ), preventive behaviours ( 28.79 vs. $30.75 ; p<0.001$ ), depression ( 4.38 vs. $6.23 ; p<0.001$ ), anxiety (3.31 vs. 5.37; $p<0.001)$, and stress $(6.17$ vs. $7.65 ; p<0.001)$ were statistically significantly lower in males than in females. No statistically significantly differences were observed between females and males in the scores of subjective well-being (11.35 vs. $12.79 ; p>0.05)$.

\section{Associations Between COVID-19-Related Factors, Mental Health Problems, and Subjective Well-Being}

Correlation analysis was initially performed to explore the relationships among the COVID19-related factors, mental health problems, and subjective well-being (Table 4). Higher age was significantly positively correlated with worry, perceived severity, preventive behaviours, depression, anxiety, and stress. Female gender was significantly positively correlated worry, preventive behaviours, depression, anxiety, and stress. Worry was significantly positively correlated with perceived severity, preventive behaviours, depression, anxiety, and stress, while it was significantly negatively correlated with subjective well-being. Perceived control was significantly positively correlated with preventive behaviours and subjective well-being, whereas it was significantly negatively correlated with depression, anxiety, and stress. Perceived severity was significantly positively correlated with preventive behaviours, depression, anxiety, and stress and that it was significantly negatively correlated with subjective wellbeing. Preventive behaviours were significantly positively correlated with depression, anxiety, and stress, and it was significantly negatively correlated with subjective well-being. Subjective well-being was significantly negatively correlated with depression, anxiety, and stress. 
Table 3 Gender differences across the study variables

\begin{tabular}{|c|c|c|c|c|c|c|c|}
\hline Level & Gender & $\mathrm{N}$ & Mean & SD & $\mathrm{t}$ & df & $p$ \\
\hline \multirow[t]{2}{*}{ Worry } & Males & 121 & 3.60 & 0.92 & \multirow[t]{2}{*}{-2.00} & \multirow[t]{2}{*}{243} & \multirow[t]{2}{*}{0.04} \\
\hline & Females & 124 & 3.83 & 0.93 & & & \\
\hline \multirow[t]{2}{*}{ Perceived control } & Males & 121 & 3.50 & 0.98 & \multirow[t]{2}{*}{-0.73} & \multirow[t]{2}{*}{243} & \multirow[t]{2}{*}{0.47} \\
\hline & Females & 124 & 3.59 & 1.02 & & & \\
\hline \multirow[t]{2}{*}{ Perceived severity } & Males & 121 & 3.50 & 1.13 & \multirow[t]{2}{*}{-1.23} & \multirow[t]{2}{*}{243} & \multirow[t]{2}{*}{0.22} \\
\hline & Females & 124 & 3.68 & 1.08 & & & \\
\hline \multirow[t]{2}{*}{ Preventive behaviours } & Males & 121 & 28.79 & 4.42 & \multirow[t]{2}{*}{-3.48} & \multirow[t]{2}{*}{243} & \multirow[t]{2}{*}{0.00} \\
\hline & Females & 124 & 30.75 & 4.37 & & & \\
\hline \multirow[t]{2}{*}{ Depression } & Males & 121 & 4.38 & 4.50 & \multirow[t]{2}{*}{-2.86} & \multirow[t]{2}{*}{234.34} & \multirow[t]{2}{*}{0.00} \\
\hline & Females & 124 & 6.23 & 5.61 & & & \\
\hline \multirow[t]{2}{*}{ Anxiety } & Males & 121 & 3.31 & 3.20 & \multirow[t]{2}{*}{-4.32} & \multirow[t]{2}{*}{228.79} & \multirow[t]{2}{*}{0.00} \\
\hline & Females & 124 & 5.37 & 4.23 & & & \\
\hline \multirow[t]{2}{*}{ Stress } & Males & 121 & 6.17 & 4.95 & \multirow[t]{2}{*}{-2.13} & \multirow[t]{2}{*}{237.04} & \multirow[t]{2}{*}{0.03} \\
\hline & Females & 124 & 7.65 & 5.95 & & & \\
\hline \multirow[t]{2}{*}{ Subjective well being } & Males & 121 & 12.79 & 5.35 & \multirow[t]{2}{*}{1.94} & \multirow[t]{2}{*}{239.14} & \multirow[t]{2}{*}{0.05} \\
\hline & Females & 124 & 11.35 & 6.23 & & & \\
\hline
\end{tabular}

Following to correlation analysis, four hierarchical regression analyses were performed to determine which COVID-19-related variables uniquely contribute to mental health and subjective well-being after controlling for age and gender (see Table 5). In the first regression model, the age and gender were entered first in step 1 and significantly predicted $5 \%$ of the variance in depression scores, $F(2,243)=6.66$, $R=.23, R^{2}=.05, p<0.01$, with older age and female gender being significant predictors of depression. The COVID-19-related factors were entered next and significantly predicted an additional $23 \%$ of the variance in depression scores, $F(6,243)=15.83$, $R=.54, R^{2}=.29, \Delta R^{2}=.23, p<0.01$, with higher worry, perceived severity, and lower perceived control being significant predictors of depression. In the second regression model, older age and female gender in step 1 significantly predicted 10 of the variance in anxiety $F(2,243)=12.61, R=.31, R^{2}=.10, p<0.01$. In step 2 , higher worry, perceived severity, and lower perceived control significantly predicted an additional $22 \%$ of the variance in anxiety, $F(6,243)=18.11, R=.56, R^{2}=.31, \Delta R^{2}=$ $.22, p<0.01$. In the third regression model, a significant contribution of older age and female gender (4\% of variance) in stress was observed in step $1, F(2,243)=4.84$, $R=.20, R^{2}=.04, p<0.01$. Entering COVID-19-related factor significantly contributed to the model by explaining an additional of $14 \%$ of the variance in depression, $F(6,243)=8.69, R=.43, R^{2}=.18, \Delta R^{2}=.14, p<0.01$. Here, worry and perceived severity were significant positive predictors of depression while perceived controllability was a significant negative predictor of depression. In the final regression model, no significant age and gender effects were observed in the prediction of subjective well-being in step $1, F(2,243)=2.14, R=.13, R^{2}=.02, p>0.05$. In step 2, inclusion of COVID-19 related factors accounted for a significant amount of variance $(22 \%)$ in the prediction of subjective well-being, $F(6,243)=11.42, R=.47, R^{2}=.22, \Delta R^{2}=.21$, $p<0.01$. In this model, worry, perceived severity, and preventive behaviours were significant negative predictors of subjective well-being, while perceived controllability was a significant positive predictor of subjective well-being. 


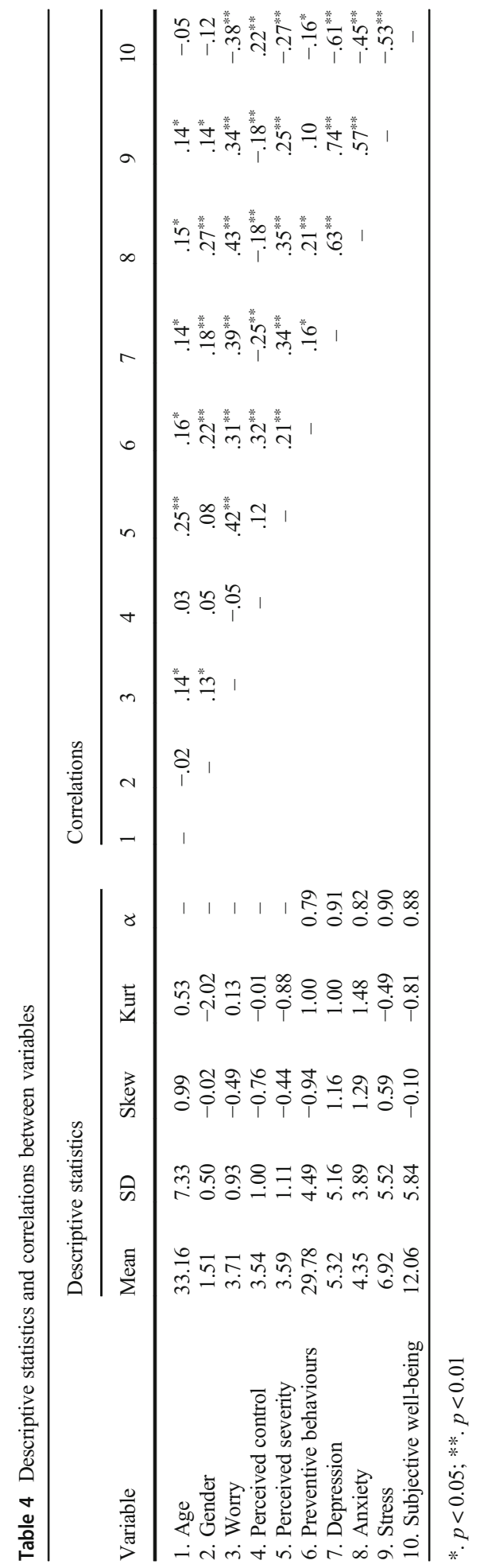




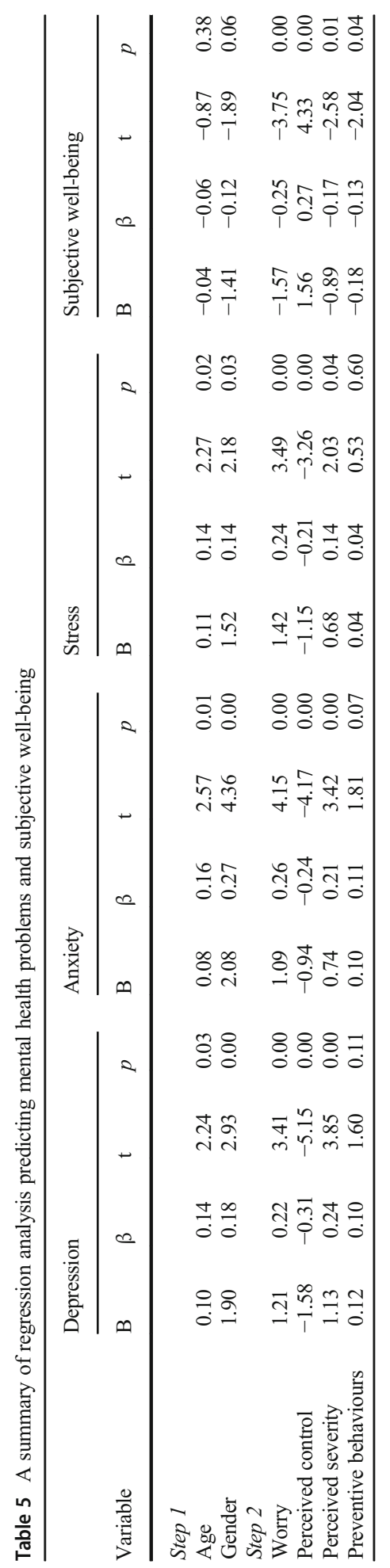




\section{Discussion}

This study investigated the prevalence of mental health problems experienced by HCWs during the COVID-19 pandemic and aimed to identify the role of psychological and behavioural factors in predicting mental health and well-being. The prevalence of depression, anxiety, and stress symptoms among the HCWs were, respectively, $12.65 \%, 9.40 \%$, and $6.10 \%$. These rates were relatively lower than those of previously reported mental health problems. A study conducted Turkey reported that the prevalence of depression, anxiety, and distress symptoms among the HCWs were $77.6 \%, 60.2 \%, 50.4 \%$, and $76.4 \%$, respectively (Şahin et al. 2020). High levels of anxiety (23.2\%), depression (22.8\%), and insomnia (38.9\%) in HCWs were also documented from other countries such as China, Spain, and Italy (Di Tella et al. 2020; Lai et al. 2020; Pappa et al. 2020; Odriozola-González et al. 2020). Contrary to these findings, our results are in line with the results of the study conducted in Singapore which demonstrated that that the prevalence of mental health problems among HCWs during COVID-19 was estimated as $14.5 \%$ for anxiety, $8.9 \%$ for depression, and $6.6 \%$ for stress (Tan et al. 2020). The variations between the current study and previous studies could be attributed to several reasons such as using different methodologies in studies or different classifications of the same measure even because using same measure may lead to different outcomes under different context (Pappa et al. 2020). The differences in the results may also be due to the fact that the psychological support units were activated at the very beginning of the pandemic in the hospital that constitutes the sample. Furthermore, the results indicated that females tend to experience more depression, anxiety, and stress and engage in preventive behaviours. These results are consistent with previous studies conducted during pandemic (Pappa et al. 2020; Yildırım and Arslan 2020). Overall, mental health problems seem to be very common among HCWs during the COVID-19 pandemic. Hence, our results show that providing psychological support is important to prevent mental health problems experienced by the HCWs during and after the pandemic.

In line with literature, our results indicated that female gender was a significant predictor of depression, anxiety, and stress. A study from China reported severe depression, anxiety, and distress symptoms among nurses, female, and frontline workers (Lai et al. 2020). A wealth of evidence suggests that female gender emerged as risk factors for anxiety and depression (Zhang et al. 2020; Zheng et al. 2020). Regarding age difference, we found that higher age was associated with greater depression, anxiety, and stress. There is inconsistency regarding age differences in reporting mental health problems. Rossi et al. (2020) showed that being younger age amidst HCWs working in pandemic were associated with greater anxiety, depression, and stress level, whereas Pan et al. (2020) showed that older age in HCWs was associated with higher generalized anxiety and somatization symptoms. Moreover some studies reported that mental health problems in HCWs are not related with age (Liu et al. 2020; Zheng et al. 2020). Our results can be explained by the notion that HCWs have tendency to experience mental problems during pandemic due to various factors such as feeling more burnout, excessive workload, and concerning about contracting and transmitting the virus to their family members.

The regression model for the prediction of anxiety, depression, stress, and well-being suggests that while worry and perceived severity were significant positive predictors of mental health problems, they were significant negative predictors of subjective well-being. Perceived control was a significant negative predictor of mental health problems and significant positive predictor of subjective well-being. These suggest that HCWs who struggle to cope with 
pandemic-related stressors in adaptive ways, by experiencing more worries and severity of the disease and less perceived control of the disease, may be more vulnerable to developing the symptoms of mental health problems and poor subjective well-being. These findings are in line with other recent studies that have presented the roles of worry, severity, and controllability in contributing to mental health and well-being during the COVID-19 pandemic (de Zwart et al. 2009; Puci et al. 2020; Yıldırım et al. 2020a; Yıldırım and Güler 2020).

In the same vein, preventive behaviours emerged as a significant predictor of subjective well-being but not mental health problems. This suggests that HCWs who actively engage in preventive behaviours against the COVID-19 pandemic appeared to be more vulnerable to experience less subjective well-being, but not necessarily developing psychiatric symptoms. Subjective well-being refers to temporal experiences of frequent positive affect, infrequent negative affect, and satisfaction with life (Diener et al. 1999). The impact of preventive behaviours on human functioning may have been appeared temporarily. Recent evidence reported the positive role of preventive behaviours on general health, resilience, and psychological health (Yıldırım and Arslan 2020; Yıldırım and Güler 2020).

\section{Limitations and Implications}

The findings of this study should be considered in the light of several methodological limitations that should be pointed out for future research. First, the data for this study was collected using a convenience sampling approach, and the emerging findings could thus not be generalized to all HCWs. Second, a cross-sectional design was employed to investigate the association between the psychological factor, behavioural factors, mental health, and wellbeing. Future research is warranted to examine how psychological and behavioural factors mediate the impact of COVID-19-related stressors on mental health and well-being using longitudinal designs. Third, self-reported measures, which are subjected to biases and limitations, are viewed another important limitation of this study, and future studies could be caried out using different data collection approaches physiological measures and peers reports to minimize the subject-related biases that could have influenced the present findings. Four, controllability, anxiety, and severity were assessed using single items in this study. This could have limited the reliability of the present findings. Future research should assess the abovementioned variables using the standardized scales with multiple items where available. Finally, worry, severity, controllability, and preventive behaviours were examined as predictors of mental health and well-being of HCWs in the context of pandemic. There is a need to understand the predictive roles of other risk and protective factors in relation to mental health and well-being in the face of adversity. The current findings cannot be generalized to other samples.

Despite the abovementioned limitations, the present findings offer important implications for research and practices by providing an in-depth understanding of the association between psychological factors, behavioural factors, mental health, and well-being in HCWs during the COVID-19 pandemic. Identifying the risk and protective factors of mental health and wellbeing is a vital step to tailor the development of intervention strategies to foster mental health and well-being. First, the findings indicated that some psychological factors (i.e. worry) play important risk factors in developing the symptoms of poor mental health and well-being in HCWs. However, other psychological factors (i.e. perceived severity and perceived controllability) and behavioural factors (i.e. preventive behaviours) function as mitigatory roles on 
HCWs' mental health and well-being. Strategies aimed at fostering protective factors including psychological and behavioural factors might be useful to help HCWs in overcoming COVID-19-related stressors and in promoting their mental health and well-being. As such, mental health providers could design interventions to identify and promote HCWs' psychological strengths, resources, and protective behaviours that contribute to their mental health and well-being. For example, mental health providers can organize activities in healthcare settings or online that foster to the development of psychological resources and adaptive behaviours to promote the ability to bounce back from stressful situation, ultimately, enhancing their mental health and well-being. Intervention strategies focusing on protective factors both psychological and behavioural are therefore essential to enhance the mental health and well-being of HCWs.

In conclusion, the findings in the present study worry is a critical risk factor in developing poor mental health and well-being among HCWs while beliefs about the severity and controllability of a disease and preventive behaviours against the disease serve as promotive psychological and behavioural resources to contribute to mental health and well-being. Undoubtedly, there will be increased demand for mental health and well-being services in the coming years. It is indispensable that primary care and mental healthcare providers be equipped to cope with ongoing stressors effectively. Assessing HCWs' mental health and well-being and their associated risk and protective factors should be a focal point of any evaluation. The increase in telepsychotherapy may give HCWs a valuable access to high-quality resources and services that can foster positive mental health and well-being outcomes during the current and any possible upcoming pandemics.

Acknowledgements We thank to all participants who voluntarily contributed to this study.

Funding The authors received no financial support for the research, authorship, and/or publication of this article.

\section{Declarations}

Ethics Approval and Consent to Participate All procedures performed in studies involving human participants were in accordance with the ethical standards of the institutional and/or national research committee and with the 1964 Helsinki declaration and its later amendments or comparable ethical standards. Consent was obtained from all participants included in the study.

Conflict of Interest The authors declare no conflicts of interest.

\section{References}

Andersen, M. R., Smith, R., Meischke, H., Bowen, D., \& Urban, N. (2003). Breast cancer worry and mammography use by women with and without a family history in a population-based sample. Cancer Epidemiology and Prevention Biomarkers, 12(4), 314-320.

Bai, Y., Lin, C. C., Lin, C. Y., Chen, J. Y., Chue, C. M., \& Chou, P. (2004). Survey of stress reactions among health care workers involved with the SARS outbreak. Psychiatric services (Washington, D.C.), 55(9), 1055-1057. https://doi.org/10.1176/appi.ps.55.9.1055. 
Bashirian, S., Jenabi, E., Khazaei, S., Barati, M., Karimi-Shahanjarini, A., Zareian, S., Rezapur-Shahkolai, F., \& Moeini, B. (2020). Factors associated with preventive behaviours of COVID-19 among hospital staff in Iran in 2020: An application of the protection motivation theory. Journal of Hospital Infection, 105(3), 430-433.

Boonen, A. (2010). Towards a better understanding of the role of psychological variables in arthritis outcome research. Arthritis Research and Therapy, 12(1), 106. https://doi.org/10.1186/ar2922.

Carmassi, C., Foghi, C., Dell'Oste, V., Cordone, A., Bertelloni, C. A., Bui, E., \& Dell'Osso, L. (2020). PTSD symptoms in healthcare workers facing the three coronavirus outbreaks: What can we expect after the COVID-19 pandemic. Psychiatry Research, 292, 113312. https://doi.org/10.1016/j.psychres.2020.113312.

Center for Systems Science and Engineering (2021). Coronavirus COVID-19 global cases at Johns Hopkins University. Available from https://coronavirus.jhu.edu/map.html

Chou, R., Dana, T., Buckley, D. I., Selph, S., Fu, R., \& Totten, A. M. (2020). Epidemiology of and risk factors for coronavirus infection in health care workers: A living rapid review. Annals of Internal Medicine, 173(2), 120-136.

de Zwart, O., Veldhuijzen, I. K., Elam, G., Aro, A. R., Abraham, T., Bishop, G. D., Voeten, H. A. C. M., Richardus, J. H., \& Brug, J. (2009). Perceived threat, risk perception, and efficacy beliefs related to SARS and other (emerging) infectious diseases: Results of an international survey. International Journal of Behavioral Medicine, 16(1), 30-40. https://doi.org/10.1007/s12529-008-9008-2.

Di Tella, M., Romeo, A., Benfante, A., \& Castelli, L. (2020). Mental health of healthcare workers during the COVID-19 pandemic in Italy. Journal of Evaluation in Clinical Practice, 26(6), 1583-1587. https://doi.org/ 10.1111 jep. 13444 .

Diener, E., Suh, E. M., Lucas, R. E., \& Smith, H. L. (1999). Subjective well-being: Three decades of progress. Psychological Bulletin, 125(2), 276-302.

Eser, E., Çevik, C., Baydur, H., Güneș, S., Esgin, T. A., Öztekin, Ç. S., Eker, E., Gümüşsoy, U., Eser, G. B., \& Özyurt, B. (2019). Reliability and validity of the Turkish version of the WHO-5, in adults and older adults for its use in primary care settings. Primary Health Care Research \& Development, 20(e100), 1-7. https:// doi.org/10.1017/S1463423619000343.

Hao, F., Tan, W., Jiang, L., Zhang, L., Zhao, X., Zou, Y., Hu, Y., Luo, X., Jiang, X., McIntyre, R. S., Tran, B., Sun, J., Zhang, Z., Ho, R., Ho, C., \& Tam, W. (2020). Do psychiatric patients experience more psychiatric symptoms during COVID-19 pandemic and lockdown? A case-control study with service and research implications for immunopsychiatry. Brain, Behavior, and Immunity, 87, 100-106. https://doi.org/10.1016/j. bbi.2020.04.069.

Kang, L., Li, Y., Hu, S., Chen, M., Yang, C., Yang, B. X., Wang, Y., Hu, J., Lai, J., Ma, X., Chen, J., Guan, L., Wang, G., Ma, H., \& Liu, Z. (2020). The mental health of medical workers in Wuhan, China dealing with the 2019 novel coronavirus. The Lancet. Psychiatry, 7(3), e14. https://doi.org/10.1016/S2215-0366(20) 30047-X.

Lai, J., Ma, S., Wang, Y., Cai, Z., Hu, J., Wei, N., Wu, J., Du, H., Chen, T., Li, R., Tan, H., Kang, L., Yao, L., Huang, M., Wang, H., Wang, G., Liu, Z., \& Hu, S. (2020). Factors associated with mental health outcomes among health care workers exposed to coronavirus disease 2019. JAMA Network Open, 3(3), e203976. https://doi.org/10.1001/jamanetworkopen.2020.3976.

Lee, S. M., Kang, W. S., Cho, A. R., Kim, T., \& Park, J. K. (2018). Psychological impact of the 2015 MERS outbreak on hospital workers and quarantined hemodialysis patients. Comprehensive Psychiatry, 87, 123127. https://doi.org/10.1016/j.comppsych.2018.10.003.

Liu, C. Y., Yang, Y. Z., Zhang, X. M., Xu, X., Dou, Q. L., Zhang, W. W., \& Cheng, A. (2020). The prevalence and influencing factors in anxiety in medical workers fighting COVID-19 in China: A cross-sectional survey. Epidemiology and Infection, 148, e98. https://doi.org/10.1017/S0950268820001107.

Lovibond, S. H., \& Lovibond, P. F. (1995). Manual for the depression anxiety \& stress scales (2nd ed.). Sydney: Psychology Foundation.

Maunder, R. G., Lancee, W. J., Rourke, S., Hunter, J. J., Goldbloom, D., Balderson, K., Petryshen, P., Steinberg, R., Wasylenki, D., Koh, D., \& Fones, C. S. (2004). Factors associated with the psychological impact of severe acute respiratory syndrome on nurses and other hospital workers in Toronto. Psychosomatic Medicine, 66(6), 938-942. https://doi.org/10.1097/01.psy.0000145673.84698.18.

Odriozola-González, P., Planchuelo-Gómez, Á., Irurtia, M. J., \& de Luis-García, R. (2020). Psychological symptoms of the outbreak of the COVID-19 confinement in Spain. Journal of health psychology, 1359105320967086. Advance online publication. https://doi.org/10.1177/1359105320967086.

Pan, X., Xiao, Y., Ren, D., Xu, Z. M., Zhang, Q., Yang, L. Y., Liu, F., Hao, Y. S., Zhao, F., \& Bai, Y. H. (2020). Prevalence of mental health problems and associated risk factors among military healthcare workers in specialized COVID-19 hospitals in Wuhan, China: A cross-sectional survey. Asia-Pacific psychiatry : official journal of the Pacific Rim College of Psychiatrists, e12427. Advance online publication. https:// doi.org/10.1111/appy.12427. 
Pappa, S., Ntella, V., Giannakas, T., Giannakoulis, V. G., Papoutsi, E., \& Katsaounou, P. (2020). Prevalence of depression, anxiety, and insomnia among healthcare workers during the COVID-19 pandemic: A systematic review and meta-analysis. Brain, Behavior, and Immunity, 88, 901-907. https://doi.org/10.1016/j.bbi.2020. 05.026 .

Puci, M. V., Nosari, G., Loi, F., Puci, G. V., Montomoli, C., \& Ferraro, O. E. (2020). Risk perception and worries among health care workers in the COVID-19 pandemic: Findings from an Italian survey. Healthcare, 8(4), 535. https://doi.org/10.3390/healthcare8040535.

Rogers, R. W. (1975). A protection motivation theory of fear appeals and attitude change1. The Journal of Psychology, 91(1), 93-114. https://doi.org/10.1080/00223980.1975.9915803.

Rossi, R., Socci, V., Pacitti, F., Di Lorenzo, G., Di Marco, A., Siracusano, A., \& Rossi, A. (2020). Mental health outcomes among frontline and second-line health care workers during the coronavirus disease 2019 (COVID-19) pandemic in Italy. JAMA Network Open, 3(5), e2010185. https://doi.org/10.1001/ jamanetworkopen.2020.10185.

Şahin, M. K., Aker, S., Şahin, G., \& Karabekiroğlu, A. (2020). Prevalence of depression, anxiety, distress and insomnia and related factors in healthcare workers during COVID-19 pandemic in Turkey. Journal of Community Health, 45(6), 1168-1177. https://doi.org/10.1007/s10900-020-00921-w.

Sarıçam, H. (2018). The psychometric properties of Turkish version of depression anxiety stress scale-21 (DASS-21) in health control and clinical samples. Journal of Cognitive Behavioral Psychotherapy and Research, 7, 19-30.

Staehr, J. K. (1998). The use of well-being measures in primary health care -the DepCare project. World health organization regional office for Europe: Well-being measures in primary health care-the DepCare project. World Health Organization.

Tan, B., Chew, N., Lee, G., Jing, M., Goh, Y., Yeo, L., Zhang, K., Chin, H. K., Ahmad, A., Khan, F. A., Shanmugam, G. N., Chan, B., Sunny, S., Chandra, B., Ong, J., Paliwal, P. R., Wong, L., Sagayanathan, R., Chen, J. T., Ng, A., et al. (2020). Psychological impact of the COVID-19 pandemic on health care workers in Singapore. Annals of Internal Medicine, 173(4), 317-320. https://doi.org/10.7326/M20-1083.

Vilhena, E., Pais-Ribeiro, J., Silva, I., Pedro, L., Meneses, R. F., Cardoso, H., ... \& Mendonça, D. (2014). Psychosocial factors as predictors of quality of life in chronic Portuguese patients. Health and Quality of Life Outcomes, 12(1), 1-11.

Witte, K. (1996). Predicting risk behaviors: Development and validation of a diagnostic scale. Journal of Health Communication, 1(4), 317-342.

World Health Organization. (2020). COVID 19 Public Health Emergency of International Concern (PHEIC). Global research and innovation forum: towards a research roadmap. https://www.who.int/publications/m/ item/covid-19-public-health-emergency-of-international-concern-(pheic)-global-research-and-innovationforum

Xiang, Y. T., Yang, Y., Li, W., Zhang, L., Zhang, Q., Cheung, T., \& Ng, C. H. (2020). Timely mental health care for the 2019 novel coronavirus outbreak is urgently needed. The lancet. Psychiatry, 7(3), 228-229. https:// doi.org/10.1016/S2215-0366(20)30046-8.

Yıldırım, M., \& Arslan, G. (2020). Exploring the associations between resilience, dispositional hope, preventive behaviours, subjective well-being, and psychological health among adults during early stage of COVID-19. Current Psychology, 1-11. https://doi.org/10.1007/s12144-020-01177-2.

Yıldırım, M., \& Güler, A. (2020). COVID-19 severity, self-efficacy, knowledge, preventive behaviors, and mental health in Turkey. Death Studies, 1-8. https://doi.org/10.1080/07481187.2020.1793434.

Yıldırım, M., Arslan, G., \& Aziz, I. A. (2020a). Why do people high in COVID-19 worry have more mental health disorders? The roles of resilience and meaning in life. Psychiatria Danubina, 32(3-4), 505-512.

Yıldırım, M., Arslan, G., \& Özaslan, A. (2020b). Perceived risk and mental health problems among healthcare professionals during COVID-19 pandemic: Exploring the mediating effects of resilience and coronavirus fear. International Journal of Mental Health and Addiction, 1-11. https://doi.org/10.1007/s11469-02000424-8.

Yıldırım, M., Geçer, E., \& Akgül, Ö. (2021a). The impacts of vulnerability, perceived risk, and fear on preventive behaviours against COVID-19. Psychology, Health \& Medicine, 26(1), 35-43. https://doi.org/ 10.1080/13548506.2020.1776891.

Yıldırım, M., Özaslan, A., \& Arslan, G. (2021b). Perceived risk and parental coronavirus anxiety in healthcare workers: A moderated mediation role of coronavirus fear and mental well-being. Psychology, Health \& Medicine, 1-12. https://doi.org/10.1080/13548506.2021.1871771.

Zhang, W. R., Wang, K., Yin, L., Zhao, W. F., Xue, Q., Peng, M., Min, B. Q., Tian, Q., Leng, H. X., Du, J. L., Chang, H., Yang, Y., Li, W., Shangguan, F. F., Yan, T. Y., Dong, H. Q., Han, Y., Wang, Y. P., Cosci, F., \& Wang, H. X. (2020). Mental health and psychosocial problems of medical health workers during the COVID-19 epidemic in China. Psychotherapy and Psychosomatics, 89(4), 242-250. https://doi.org/10. 1159/000507639. 
Zheng, R., Zhou, Y., Qiu, M., Yan, Y., Yue, J., Yu, L., Lei, X., Tu, D., \& Hu, Y. (2020). Prevalence and associated factors of depression, anxiety, and stress among Hubei pediatric nurses during COVID-19 pandemic. Comprehensive psychiatry, 104, 152217. Advance online publication. https://doi.org/10.1016/j. comppsych.2020.152217.

Publisher's Note Springer Nature remains neutral with regard to jurisdictional claims in published maps and institutional affiliations. 